\title{
Pelvic organ prolapse: A primer for urologists
}

\author{
Michel Bureau, MD; Kevin V. Carlson, MD \\ Section of Urology, Department of Surgery, University of Calgary, Calgary, AB, Canada
}

Cite as: Can Urol Assoc J 2017;11 (6Supp|2):S125-30. http://dx.doi.org/10.5489/cuaj.4634

See related commentary on page S131.

\section{Abstract}

Pelvic organ prolapse (POP) results from weakness or injury of the pelvic floor supports with resulting descent of one or more vaginal compartments (anterior, apical and/or posterior). Women typically become symptomatic from the bulging vaginal wall or related organ dysfunction once this descent reaches the introitus. POP is a common condition, affecting more than half of adult women. Many women presenting to an urologist for stress urinary incontinence or overactive bladder will have associated POP; therefore, it is important for urologists who treat these conditions to be familiar with its diagnosis and management. While POP is part of the core urology training curriculum in some jurisdictions, it is not in Canada. ${ }^{1}$ This article reviews the diagnosis of POP, including pertinent symptoms to query in the history, important facets of a systematic pelvic examination, and the appropriate use of ancillary tests. Treatment options are also discussed, including conservative measures, pessaries, and various reconstructive and obliterative techniques.

\section{Introduction}

Pelvic organ prolapse (POP) and stress urinary incontinence (SUI) are the result of inadequate pelvic floor support, of which three anatomic levels have been described ${ }^{2,3}$ (Fig. 1). The International Continence Society defines pelvic organ prolapse (POP) as: "the descent of one or more of: the anterior vaginal wall, the posterior vaginal wall, and the apex of the vagina (cervix/uterus) or vault (cuff) after hysterectomy." ${ }^{4}$ Anterior compartment prolapse and SUI are caused by a weakness or injury of the pubocervical fascia with resulting descent of the bladder (cystocele) and/or bladder neck (SUI). Posterior compartment prolapse is caused by weakness or injury of the rectovaginal septum resulting in protrusion of the rectum (rectocele) and/or the small bowel (enterocele). Apical compartment prolapse refers to the decent of the uterus/cervix or the vaginal cuff and small bowel in posthysterectomy patients. Prolapse in an isolated segment can occur, but most commonly, more than one compartment is involved.

POP is a common condition; however, its true prevalence is difficult to determine as POP typically remains asymptomatic until it descends to the hymenal ring or beyond. ${ }^{5}$ In questionnaire-based population studies of non-pregnant adult women the prevalence of symptomatic POP ranges from $2.9-12.1 \%{ }^{6,7}$ however, when basing prolapse on examination findings, the prevalence increases to $75-76 \%$, with $37-38 \%$ having stage II or higher. ${ }^{7,8}$ In postmenopausal women enrolled in the Women's Health Initiative, the prevalence of POP was $41 \%$ in patients with a uterus and $38 \%$ in subjects who had had a prior hysterectomy. ${ }^{9}$

Well-established risk factors for POP include age, parity, and obesity. ${ }^{10}$ Other risk factors include forceps delivery, infant birth weight $>4500 \mathrm{~g}$, constipation, smoking, family history of POP, connective tissue disease, occupation entailing heavy lifting, previous hysterectomy, and ethnic origin. ${ }^{10}$

\section{Evaluation}

Symptoms described by patients with POP may be due to the prolapse itself or to associated or coexistent dysfunction of the bladder, bowel, or pelvic floor. Physical symptoms commonly reported by patients include sensation of a bulge, heaviness or pressure in the vagina, the feeling of "sitting on a ball," or that "something is falling out." Functional symptoms can provide a clue as to what compartments may be prolapsed, but correlate poorly with the degree of anatomical descent. These include storage and/or voiding lower urinary tract symptoms, constipation or sensation of incomplete emptying when passing stools, needing to manually splint the vagina to facilitate emptying of the rectum, fecal or urinary incontinence, and dyspareunia. ${ }^{10,11}$ Table 1 presents complaints that may be described by patients with POP. It is important to keep in mind that none of the symptoms associated with POP are specific except for the sensation of bulging. Therefore, the clinician should have an extensive knowledge 


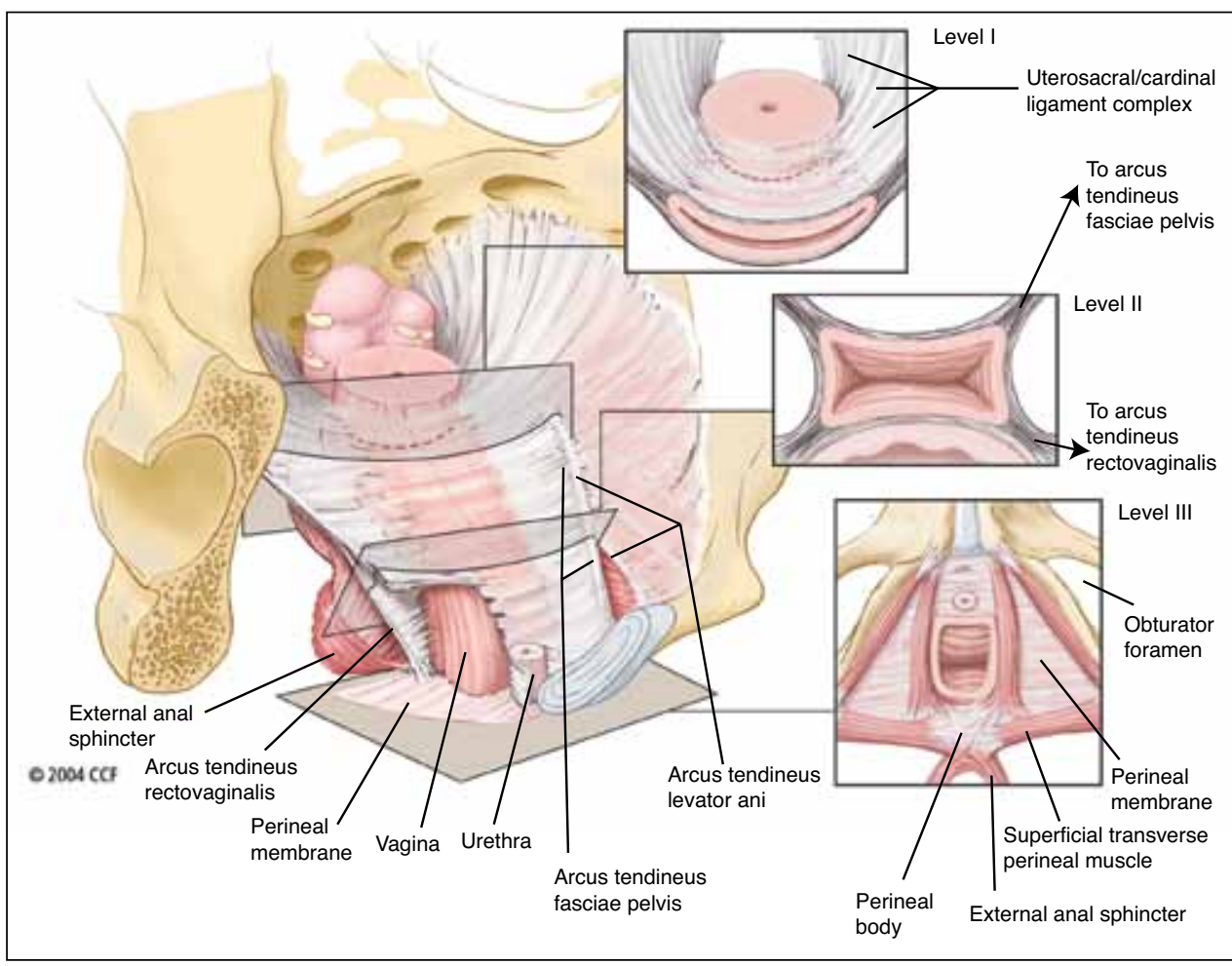

Fig. 1. Integrated levels of support: Illustration of the normal vaginal axis and the three levels of support of the vagina and uterus from the perspective of a standing woman. In level I, the endopelvic fascia suspends the upper vagina and cervix from the lateral pelvic walls. Fibers of level I extend both vertically and posteriorly toward the sacrum. In level II, the vagina is attached to the arcus tendineus fasciae pelvis and superior fascia of the levator ani muscles. In level III, the distal vagina is supported by the perineal membrane muscles. The insets show transverse sections made through the vagina perpendicular to the normal axis at each level. Reproduced from: Barber MD. Contemporary views on female pelvic anatomy. Cleve Clin J Med 2005;72:S3-11. With permission from Cleveland Clinic Foundation. (C2005 Cleveland Clinic Foundation. All rights reserved.

of the differential diagnosis of pelvic complaints and use caution when counselling a patient regarding the expectations of a treatment for their POP. Finally, the psychological impacts of POP should not be underestimated. Urinary and lower gastrointestinal tract dysfunction can be a significant source of embarrassment in women and may contribute to social isolation, and discomfort or pain caused by the prolapsed vagina may lead to restriction of activities and/or intimacy.

When evaluating a patient with POP, it is important to question all aspects of pelvic floor dysfunction. The clinician should gather information regarding symptoms directly caused by the prolapse and inquire about urinary, digestive and sexual symptoms. Past medical history should be reviewed, as it may have an impact on the treatment options. In addition, a complete gynecological and obstetric history should be taken. It is critical to determine if a patient is sexually active or desires to be, as this may also factor into treatment decisions. A variety of validated questionnaires exist to help in the assessment of the patient's condition and its impact on her quality of life. ${ }^{12,13}$

Physical examination of women with POP is traditionally performed in the dorsal lithotomy position. Ideally, the exam should also be done in the standing position espe- cially if the POP described by the patient is not initially appreciated. ${ }^{14}$ Furthermore, as the degree of prolapse may be impacted by the menstrual cycle and/or fatigue of the pelvic floor muscles (PFMs), the exam may need to be scheduled at a time when prolapse is most likely to be demonstrated. The external genitalia are first inspected, then the vestibule and urethra are examined. Estrogenization of the tissues and the presence of scarring from prior surgery or obstetrical trauma should be noted. A Sims speculum or the posterior blade of a bivalve speculum is used to depress the posterior wall of the vagina to better assess the anterior wall, and vice versa to assess the posterior wall. The cervix or vaginal cuff can be examined using a complete bivalve speculum. Subsequently, a bimanual exam should be done to rule out other gynecological conditions. Finally, rectal and rectovaginal exams are performed to evaluate posterior POP and the perineal body.
Table 1. Symptoms commonly reported by patients with POP ${ }^{10,11}$

Vaginal:
-
- Bulging sensation
- Bleeding from eroded vaginal mucosa

Urinary:

- Incontinence

- Frequency and urgency

- Sensation of incomplete emptying

- Weak stream

- Intermittency

Straining or need to change position to empty the bladder Manual reduction of POP to empty the bladder

\section{Gastrointestinal:}

- Constipation

- Incontinence

- Sensation of incomplete emptying

- Manual reduction of POP or pressure on the perineum to empty the rectal ampulla (vaginal splinting)

\section{Sexual:}

- Dyspareunia

- Coital incontinence

\section{Other:}

- Pelvic discomfort, pain, or heaviness

Lower back pain

POP: pelvic organ prolapse. 
The need for additional testing depends principally on the patient's symptoms and clinician's findings. To further assess the patient's bladder function a voiding diary, patientreported outcomes (PROs), measurement of post-void residual volume, or a urodynamic study (UDS) may be useful. In postmenopausal women with vaginal bleeding, especially in the absence of ulceration of the vagina or cervix, the endometrium should be evaluated with an ultrasound and/or a biopsy..$^{15}$ In patients presenting with advanced prolapse, the ureters may be obstructed; therefore, imaging of the upper urinary tract to rule out hydronephrosis may be prudent.

Several grading systems have been developed to describe POP. The Pelvic Organ Prolapse Quantification (POP-Q) scale is one of the most commonly used and was designed to standardize assessment of POP. ${ }^{16}$ The system uses the position of six defined points measured in $\mathrm{cm}$ above or below a fixed point (the hymenal ring) while the patient is straining. Three other parameters (total vaginal length, genital hiatus, and perineal body) are also measured with the patient relaxed. The stage of prolapse can then be described based on the POP-Q score as shown in Table 2.

Diagnostic imaging to characterize a patient's POP is an emerging field of study, but in clinical practice is generally not necessary. In fact, there is often a discrepancy between radiological and surgical findings, and there is a lack of standardized criteria for the radiological diagnosis of POP. Therefore, imaging studies are mainly used in research settings. ${ }^{17}$

Urinary incontinence is a frequent condition associated with POP. Interestingly, up to $44 \%$ of patients without incontinence will develop stress urinary incontinence (SUI) once the prolapse is surgically reduced. ${ }^{18}$ This so-called latent, or occult, SUI occurs when obstruction of the outlet caused by the prolapse is corrected, thus unmasking SUI. Latent SUI should be sought by the clinician during physical examination or UDS with the prolapse manually reduced (e.g., pessary), as it may impact the treatment plan and outcomes.

It is also notable that $22-88 \%$ of patients presenting with POP have coexistent overactive bladder $(\mathrm{OAB})$ symptoms that may need to be addressed. ${ }^{19}$ The pathophysiology most likely to explain this relationship is bladder outlet obstruction, although other factors, such as activation of urothelial stretch receptors or bladder neck funnelling to allow urine to pool in the proximal urethra, may play a role. Following POP surgery, the impact on $O A B$ is difficult to predict, and there is no reliable data to guide patient counselling in this regard; however, it clearly does resolve in many cases, ${ }^{19}$ particularly with higher-stage prolapse. ${ }^{20}$

\section{Management}

A patient-centred approach is taken in the management of POP, taking into consideration the anatomic defect(s) present, effect on organ function, severity of symptoms, degree of bother and impact on quality of life, desire for sexual function, and patient preferences and expectations. Furthermore, available expertise and resources may play a role in treatment decisions. While broad treatment recommendations can be made, each patient must be managed in a highly individualized fashion.

In all cases, treatment begins with education about normal anatomy and function. Excessive stress on the pelvic floor from heavy lifting, chronic constipation, or cough should be corrected, and weight loss and smoking cessation are recommended when appropriate. ${ }^{21}$ Symptomatic urogenital atrophy should be treated with topical estrogen replacement if there are no contraindications. ${ }^{22}$ Management options include continued observation, non-surgical interventions, and surgery.

For asymptomatic women and those mildly bothered by their condition, observation is often recommended; however, if adverse sequelae of untreated prolapse - such as urinary retention, severe bowel dysfunction, or hydronephrosis - are present, treatment should be offered. Patients with advanced POP choosing observation should be reassessed regularly to ensure they do not develop any such complications.

Pelvic floor muscle training (PFMT), either self-directed or under the guidance of a therapist with specialty training, is typically suggested as an initial non-surgical modality for stages 1-3 POP. Recent evidence indicates that PFMT under the guidance of a therapist provides superior results, with significant numbers demonstrating an improvement in symptoms and by one stage on POP-Q examination. ${ }^{23-25}$ These observations have led the 5th International Consultation on Incontinence to upgrade its recommendation for this modality. ${ }^{26}$

In patients significantly bothered by their POP but who do not want surgery, and in those who are not medically fit or planning to become pregnant again, a pessary can be tried. These devices, usually made of silicone, come in a variety of shapes and sizes and are inserted in the vagina to reduce the prolapse by supporting the pelvic organs.

\begin{tabular}{|c|c|}
\hline Stage & Description \\
\hline 0 & $\begin{array}{l}\text { No prolapse. Points } A a, B a, A p, B p \text { are all }-3 \text {, and } \\
\text { either } C \text { or } D \text { is within } 2 \mathrm{~cm} \text { of } T V L\end{array}$ \\
\hline I & $\begin{array}{l}\text { Some prolapse is present, but the distal most } \\
\text { point is }>1 \mathrm{~cm} \text { above the hymen }\end{array}$ \\
\hline II & $\begin{array}{l}\text { The furthest distal point is within } 1 \mathrm{~cm} \text { of either } \\
\text { side of the hymen }\end{array}$ \\
\hline III & $\begin{array}{l}\text { The distal most point is }>1 \mathrm{~cm} \text { but }<(T V L-2) \mathrm{cm} \\
\text { beyond the hymen }\end{array}$ \\
\hline IV & $\begin{array}{l}\text { Complete eversion of the vagina, usually with } \\
\text { the leading point being the cervix or vaginal cuff. } \\
\text { The distal point is at least (TVL-2) cm beyond the } \\
\text { hymen }\end{array}$ \\
\hline
\end{tabular}


Pessaries, when properly fitted by a trained clinician, usually improve or resolve symptoms associated with POP and can also help with urinary and bowel symptoms. In women successfully fitted with a pessary, $40-60 \%$ will continue use for more than 6-12 months. ${ }^{27}$ Potential complications of these devices are vaginal discharge, bleeding, erosion, pain, constipation, and incontinence (including unmasking SUI). ${ }^{28}$ In the absence of contraindications, the concomitant use of topical estrogens is usually recommended.

Surgery for POP is indicated for women experiencing significant bother and wishing a definitive treatment. Surgery should only be done after childbearing is complete and, depending on the case, after a proper trial of conservative measures. Numerous procedures have been described and their detailed review is beyond the scope of this article. General concepts regarding the correction of POP are presented below.

POP repair procedures can be broadly divided into reconstructive and obliterative surgeries. Reconstructive procedures aim at restoring normal anatomy and function of the vaginal canal, whereas obliterative surgeries will result in the permanent and irreversible closure of the vagina.

Pelvic floor reconstructive surgery can be accomplished via transvaginal or transabdominal approaches, or a combination of both. The procedure should aim to restore each level of pelvic floor support that is felt to be defective: reconstruction of multiple compartments is often necessary. Surgery should aim to preserve vaginal length and axis in sexually active women. Surgical risks must be carefully discussed and expectations aligned. The surgery chosen should balance surgical risks with the goals of achieving a durable repair that meets the above criteria. Surgeons undertaking these operations should be skilled in vaginal dissection, have a thorough understanding of the pelvic anatomy via transvaginal and transabdominal approaches, have a broad repertoire of techniques available to tailor to the individual patient, and have the skills and resources to diagnose and manage potential complications. Even in the best of hands, and regardless of technique chosen, organ injury, neuropathic pain, and functional derangements are potential risks. Importantly, the need for reoperation for recurrent prolapse is high, owing to the nature of the tissues being reconstructed and the constant demands placed on the pelvic floor. This is particularly true with a history of higher-stage (3 or 4) POP, preoperative prolapse in more than two vaginal compartments, prior pelvic floor surgery for POP or SUI, and the presence of sexual activity. ${ }^{29,30}$

Anterior compartment prolapse was classically treated by anterior colporrhaphy, which corrects defects in the pubocervical fascia to provide support to the anterior vaginal wall and thus correct a so-called central defect cystocele. Lateral defect cystoceles, caused by attenuation or tearing of the arcus tendineus fascia pelvis (ATFP) were corrected by re-approximating the pubocervical fascia to the ATFP. Understanding that many failures of anterior vaginal repairs were due to associated weakness of vaginal apical supports (DeLancey level I), contemporary anterior repair includes re-approximation of pubocervical fascia to the vaginal apex with or without associated vaginal vault suspension.

Posterior vaginal repairs may address an enterocele, rectocele, and/or perineal body defect. Enteroceles may be addressed transvaginally via intra- or extraperitoneal approaches. Most commonly, transvaginal native tissue site-specific repairs are performed once the enterocele sac is reduced, again with or without concomitant vaginal vault suspension. More distally, posterior colporraphy restores the support to the posterior wall of the vagina by correcting defects in the rectovaginal fascia over the rectum; however, a site-specific approach obviating the need for plication may again be chosen where appropriate. Finally, perineorrhaphy is commonly performed at the time of these repairs, using sutures to reconstruct the perineal body.

Apical compartment prolapse must be addressed when present to minimize the likelihood of recurrence. This may be accomplished vaginally with uterocervical suspension to the sacrospinous ligament or with a hysterectomy followed by a high suspension to the uterosacral ligaments, or to one or both sacrospinous ligaments. It can also be corrected abdominally (open, laparoscopic, or robotic-assisted) with sacrocolpopexy or sacrohysteropexy, which suspends the vaginal apex or uterus to the longitudinal sacral ligament using a Y-shaped graft of synthetic mesh. The abdominal approach is considered the gold standard in women wishing to preserve sexual function with high-grade post-hysterectomy vault prolapse, and those requiring secondary repairs following a failed vaginal technique. ${ }^{31,32}$

In the early 2000s, transvaginal implantation of synthetic mesh became very popular for the repair of POP to address what was felt to be a very high recurrence rate following native tissue repairs; however, their use has fallen dramatically owing to warnings about serious complications issued by the US Food and Drug Administration (FDA), along with evidence that refutes their benefit in reducing risk of recurrence. ${ }^{33}$ In 2010, Health Canada released a Notice to Hospitals to inform healthcare professionals of the potential risks associated with transvaginal placement of synthetic mesh for POP and SUI. This was updated in 2014. ${ }^{34}$ These advisories highlight the observation that transvaginal use of mesh may carry a higher risk of certain complications when compared to transabdominal mesh placement or native tissue repair. They also point out that complications may not be completely correctable with additional surgeries and that the surgeon should be familiar with the device techniques and warning, as well as have proper training to implant 
them. More recently, the Canadian Urological Association issued a consensus statement discouraging the routine use of transvaginal mesh for correction of POP except in in select, more complicated cases..$^{35}$ Patients undergoing mesh implantation must be carefully consented and informed of the potential risks and the presence of this advisory.

Obliterative procedures, including total or partial colpectomy and colpocleisis, are appropriate for very carefully selected patients. Women considering these procedures should be fully informed regarding the loss of vaginal length and the inability to have sexual intercourse in the future. These procedures may provide more durable results with lower reoperation rates compared to reconstructive options. ${ }^{21}$ Moreover, they have a low complication rate and are associated with high patient satisfaction. ${ }^{36,37}$ They thus represent a viable option for patients who are no longer interested in sexual intercourse and/or are suboptimal surgical candidates.

\section{Conclusion}

POP is a prevalent condition. A comprehensive assessment of the symptoms, as well as the degree and precise location of the prolapse is essential. Education and lifestyle recommendations are first-line for all patients. From there, a highly-individualized, patient-centric approach that considers the patient's level of bother and expectations is key to a successful outcome. The stakes for surgical intervention are high and numerous techniques may be required to address these challenging conditions.

Competing interests: The authors report no competing personal or financial interests.

This paper has been peer reviewed.

\section{References}

1. Objectives of Training in Urology. Available at: http://www.royalcollege.ca/rc/faces/oracle/ webcenter/portalapp/pages/ibd. jspx;isessionid=bwUq_VEjPMmZQ5APleB-3B9FP09LON9f5y40R4WdOUlwvEOdiCA! 1821147059?_afrLoop $=844908695242680$ \&_afrWindowMode $=0$ \& afrWindowld=null\#!\%40\%40\%3F_afrWindowld\%3Dnull\%26_afrLoop\%30844908695242680\%26_ afrWindowMode\%3D0\%26_adf.ctrl-state\%3D1cqqia9qat_4. Accessed March 28, 2017.

2. DeLancey J0. Anatomic aspects of vaginal eversion after hysterectomy. Am J Obstet Gynecol 1992;166:1717-28. hrtps://doi.org/10.1016/0002-9378(92)91562-0

3. Barber MD. Contemporary views on female pelvic anatomy. Cleve Clin J Med 2005;72:S3-11. https://doi.org/10.3949/ccim.72.Suppl_4.S3

4. Abrams $P$, Cardozo L, Fall M, et al. The standardization of terminology in lower urinary tract function: Report from the Standardization Subcommittee of the International Continence Society. Urology 2003;61:37-49. hitps://doi.org/10.1016/S0090-4295(02)02243-4

5. Swift SE, Tate SB, Nicholas J. Correlation of symptoms with degree of pelvic organ support in a general population of women: What is pelvic organ prolapse. Am J Obstet Gynecol 2003;189:372-9. hitps://doi.org/10.1067/S0002-9378(03)00698-7

6. Nygaard I, Barber MD, Burgio KL, et al. Prevalence of symptomatic pelvic floor disorders in U.S. women. JAMA 2008;300:1311-6. hitps://doi.org/10.1001/jama.300.11.1311
7. Sliekerten Hove MC, Pool-Goudzwaard AL, Eijkemans MJ, et al. The prevalence of pelvic organ prolapse symptoms and signs and their relation with bladder and bowel disorders in a general female population. Int Urogynecol J Pelvic Floor Dysfunct 2009;20:1037-45. https://doi.org/10.1007/s00192-009-0902-1

8. Swift S, Woodman P, O'Boyle A, et al. Pelvic Organ Support Study (POSST): The distribution, clinical definition, and epidemiological condition of pelvic organ support defects. Am J Obstet Gynecol 2005; 192:795806. https://doi.org/10.1016/i.ajog.2004.10.602

9. Hendrix SL, Clark A, Nygaard I, et al. Pelvic organ prolapse in the Women's Health Initiative: Gravity and gravidity. Am J Obstet Gynecol 2002;186:1 160-6. https://doi.org/10.1067/mob.2002.123819

10. Jelovsek JE, Maher C, Barber MD. Pelvic organ prolapse. Lancet 2007;369:1027-38. https://doi.org/10.1016/S0140-6736(07)60462-0

11. Ellerkmann RM, Cundiff GW, Melick CF, et al. Correlation of symptoms with location and severity of pelvic organ prolapse. Am J Obstet Gynecol 2001;18:1332-8. https://doi.org/10.1067/mob.2001.119078

12. Barber MD, Maher C. Epidemiology and outcome assessment of pelvic organ prolapse. Int Urogynecol J 2013;24:1783-90. https://doi.org/10.1007/s00192-013-2169-9

13. Kelleher C, Staskin D, Cherian P, et al. Patient-reported outcome assessment. In: Abrams P, Cardozo L, Khoury S, Wein A (eds) 5th International Consultation on Incontinence. Health Publication Ltd, Paris, 2013, 389-428.

14. Kobashi KC. Evaluation and management of women with urinary incontinence and pelvic prolapse. In: Wein AJ, Kavoussi LR, Partin AW, Peters CA, editors. Campbell-Walsh Urology, Eleventh Edition. Philadelphia: Elsevier;2016:1697-1709.

15. Weissbart S, Arya L, Wein A. Gynecological evaluation before female pelvic reconstructive surgery. AUA Update Series 2016; vol 35 lesson 12.

16. Bump RC, Mattiasson A, Bø K, et al. The standardization of terminology of female pelvic organ prolapse and pelvic floor dysfunction. Am J Obstet Gynecol 1996;175:10-7. https://doi.org/10.1016/500029378(96)70243-0

17. Karram M. Preoperative evaluation and staging of patients with pelvic organ prolapse. In: Karram $M$, Maher CF, editors. Surgical management of pelvic organ prolapse. Phildadelphia: Elsevier Saunders; 2013;31-41. https://doi.org/10.1016/B978-1-4160-6266-0.00003-4

18. Brubaker L, Cundiff GW, Fine P, et al. Abdominal sacrocolpopexy with Burch colposuspension to reduce urinary stress incontinence. N Engl J Med 2006;354:1557. https://doi.org/10.1056/NEJMoa054208

19. de Boer TA, Salvatore S, Cardozo L, et al. Pelvic organ prolapse and overactive bladder. Neurourol Urodyn 2010;29:30-9. htrps://doi.org/10.1002/nau.20858

20. Miranne JM, Lopes V, Carberry CL, et al. The effect of pelvic organ prolapse severity on improvement in overactive bladder symptoms after pelvic reconstructive surgery. Int Urogynecol J 2013;24:1303. https://doi.org/10.1007/s00192-012-2000-z

21. Glass D, Brucker B, Nitti V. Treatment of pelvic organ prolapse in the frail elderly patient. AUA Update Series 2017; vol 36 lesson 3

22. Weber MA, Kleijn MH, Langendam M, et al. Local oestrogen for pelvic floor disorders: A systematic review. PLoS One 2015;10:e0136265. https://doi.org/10.1371//ournal.pone.0136265

23. Hagen $S$, Stark D, Glazener C, et al. Individualized pelvic floor muscle training in women with pelvic organ prolapse (POPPY): A multicentre, randomized, controlled trial. Lancet 2014;383:796-806. https://doi.org/10.1016/S0140-6736(13)61977-7

24. Braekken IH, Majida M, Engh ME, et al. Can pelvic floor muscle training reverse pelvic organ prolapse and reduce prolapse symptoms? An assessor-blinded, randomized, controlled trial. Am J Obstet Gynecol 2010;203:170. https://doi.org/10.1016/.j.jog.2010.02.037

25. Stupp L, Resende AP, Oliveira E, et al. Pelvic floor muscle training for treatment of pelvic organ prolapse: An assessor-blinded, randomized, controlled trial. Int Urogynecol J 2011;22:1233-9. https://doi.org/10.1007/s00192-011-1428-x

26. Dumoulin C, Hunter KF, Moore K, et al. Conservative management for female urinary incontinence and pelvic organ prolapse review 2013: Summary of the 5 th International Consultation on Incontinence. Neurourol Urodyn 2016;35:15-20. https://doi.org/10.1002/nau.22677

27. Bradley C. Pessaries and devices: Non-surgical treatment of pelvic organ prolapse and stress urinary incontinence. In: Cardozo L, Staskin D, editors. Textbook of Female Urology and Urogynecology Third Edition. Colchester: Informa Healtcare; 2010; 458. https://doi.org/10.3109/9781439807217-47

28. Sarma S, Ying T, Moore KH. Long-term vaginal ring pessary use: Discontinuation rates and adverse events. BJOG 2009;116:1715-21. https://doi.org/10.1111/i.1471-0528.2009.02380.x

29. Vergeld TFM, Weemhoff $M$, IntHout J, et al. Risk factors for pelvic organ prolapse and its recurrence: A systematic review. Int Urogynecol J 2015;26:1559-73. https://doi.org/10.1007/s00192-015-2695-8

30. Dallenbach P. To mesh or not to mesh: A review of pelvic organ reconstructive surgery. Int J Wom Health 2015;7:331-43. https://doi.org/10.2147/IJWH.S71236

31. Nygaard IE, McCreery R, Brubaker L, et al. Abdominal sacrocolpopexy: A comprehensive review. Obstet Gynecol 2004;104:805-23. htrps://doi.org/10.1097/01.A0G.0000139514.90897.07

32. Culligan PJ, Murphy M, Blackwell L, et al. Long-term success of abdominal sacral colpopexy using synthetic mesh. Am J Obstet Gynecol 2002;187:1473-82. https://doi.org/10.1067/mob.2002.129160 
Bureau et al.

33. Oversand SH, Staff AC, Spydslaug AE, et al. Long-term followup after native tissue repair for pelvic organ prolapse. Int Urogynecol J 2014;25:81-9. htrps://doi.org/10.1007/s00192-013-2166-z

34. Surgical mesh - Complications associated with transvaginal implantation for the treatment of stress urinary incontinence and pelvic organ prolapse - Notice to hospitals -Recalls \& alerts. Available at: http://www.healthycanadians.gc.ca/recall-alert-rappel-avis/hc-sc/2014/39475a- eng.php. Published May 13, 2014. Accessed February 15, 2017.

35. Welk B, Carlson K, Baverstock R, et al. Canadian Urological Association position statement on the use of transvaginal mesh July 2016. Available at: https://www.cua.org/themes/web/assets/files/cua_position_statement_on_transvaginal_mesh_v4_np.pdf. Accessed February 27, 2017.
36. FitzGerald MP, Richter HE, Bradley CS, et al. Pelvic support, pelvic symptoms, and patient satisfaction after colpocleisis. Int Urogynecol J Pelvic Floor Dysfunct 2008;19:1603-9. https://doi.org/10.1007/ s00192-008-0696-6

37. Barber MD, Maher C. Apical prolapse. Int Urogynecol J 2013;24:1815-33. https://doi.org/10.1007/ s00192-013-2172-1

Correspondence: Dr. Kevin V. Carlson, Section of Urology, Department of Surgery, University of Calgary, Calgary, AB, Canada; kevin.carlson@ahs.ca 